\title{
O CONCEITO DE MODELO COMO ESTRATÉGIA DE ENSINO
}

\section{Marlene Kramer}

Não é extraordinário que o modelo (modeling 7 ou exemplo como método de ensino tenha sido identificado já na época de Plutarco e que atualmente ainda continue a procurar seu caminho nos currf́culos dos cursos de formação de professores, tanto no ensino da enfermagem como em out ras áreas? A maioria dos programas destinados ao preparo de professoras de enfermagem enfatizam a estratégia da exposição didática e, possivelmente, da discussão em pequenos grupos; poucos programas, porém, incluem a estratégia do modelo ou exemplo, ou seja, da imitação, nos seus curriculos. Talvez isto se deva ao fato de que a maioria dos professores dos cursos de graduação em enfermagem utilizam-se das mesmas estratégias mediante as quais receberam instrução, ou a que tiveram que se adaptar quando estudantes. Consistiam, em geral, em apresentação explanatória da matéria, interrogatório indutivo e dechutivo e, na área clínica, do que poderia ser chamado de orientação tutorial.

Bandura assinala que ... virtualmente todo fenomeno de aprendizagem, resultante de experiéncias diretas, pode ocorrer na base da substituição, ou suplementação, através da observação do comportamento de outras pessoas e de suas consequências 1 . Se isto é verdade, porque não do senvolver e utilizar a estratégia do modelo nos currículos de enfermagem e nos programas de didática especial? Sabemos que estudantes e enfermeiras recém graduadas tomam as docentes, as enfermeiras do campo e as enfermeiras-chefes como modelos e consideram esses modelos como sendo eficientes,

- Traduç̋o do artigo "The Concept of Modeling as a Teaching Strategy". Nursing Forum 11 (1):48-70, 1972, por Amalia C. de Carvalho, com autorizacto da autora.

- A Palavra modeling pode ser traduzida como modelar, no sentido de modelaço. tomar como modelo, regular o seu procedimento pelo de outrem. Modelo: um objeto que se reproduz, imitando-o (Dicionário Barsa Inglés-Portugues e Dicionário Prético llustrado Lello). 
ainda que diferentes uns dos outros 2 . Um processo ensino-aprendizagem de tal magnitude não pode ser desprezado.

\section{A EVOLUÇÃO DO EMPREGO DO MODELO}

A mais antiga explicação sobre o emprego do modelo, ou comportamento igual ou semelhante, data dos escritos de Morgan e Tarde 3, em 1896. Naquele tempo a modelação * (imitação) era considerada como uma propensão inata, comparando-se ao comportamento dos patos em relação à tendência de andarem em cortejos. Essa interpretação, baseada na teoria dos instintos, atrasou de muitos anos as investigaçðes empíricas sobre a imitação. Foi desde o trabalho clássico de Miller e Dollard, denominado Aprendizagem Social e Imitação 4 , que esse assunto começou a ser sistemática e metodicamente explorado.

Quando a doutrina dos instintos caiu em descrédito, alguns psicólogos tentaram utilizar princípios associativos para justificar o comportamento imitativo. Consideraram a proximidade de tempo entre o estímulo emitido pelo modelo e a resposta (comportamento) semelhante do imitador, como condição suficiente para a ocorrência da imitação. Piaget visualiza o processo da imitação em forma circular ou como uma seqüência de imitaçðes alternadas 5 . 0 modelo emite comportamento que serve de estŕmulo para respostas (comportamentos) semelhantes por parte do imitador, um processo que se repete indefinidamente.

Teóricos associativistas descrevem uma das condições em que a imitação poderá determinar um comportamento que já faz parte do repertório do imitador. Não explicam, entretanto, a aquisição de respostas novas.

Skinner e outros psicólogos da teoria do reforço mudaram seu enfoque para a aquisição de comportamento reforçando os resultados já alcançados. Miller e Dollard, por exemplo, defendem o ponto de vista de que a condição necessária à aprendizagem através de modelos é a existência de um indivíduo motivado, que recebe a fim de reproduzir o comportamento

\footnotetext{
- No sentido de tomar como modelo, imitar. Como em Portuguẽs a palavra modelação năo tem o mesmo sentido que em Inglês, tomamos a liberdade de utilizar o termo Imitacão, que para nós significa tomar como modelo.
} 
exato do modelo. Esses tebricos consideram as tentativas iniciais do indivíduo para imitar um determinado comportamento como sendo de ensaio e erro 6.

$\mathrm{Na}$ teoria do condicionamento operante de Skinner a imitação é vista como uma forma de estímulo combinado, no qual possivelmente se dê a duplicação através de reforços diferenciais 7 . Esse processo pode ser longo e vagaroso porque o comportamento inicial pode ser imitido antes do reforço diferencial poder dar início à formação do comportamento desejado. No exemplo que se segue, o comportamento desejado pela criança é pendurar seu casaco quando entrar em casa. 0 pai (modelo) desempenha o comportamento desejado pendurando o casaco. Na próxima oportunidade, quando a criança tira o casaco e o deixa cair no chão, o pai repete o processo de pendurá-lo. Quando a criança o apanha para apresentá-lo ao pai, seu comportamento recebe reforço social. No dia seguinte, o pai repete o processo - e agora já a criança leva o casaco até o cabide e entrega-o ao pai. Segue-se o reforço. Numa próxima ocasião a própria criança pendura o casaco e seguese, novamente, o reforço, e assim por diante. (Neste exemplo existe uma condição indispensável: que a criança possua as necessárias habilidades motoras).

Sob certas condiçð̃es, alguns comportamentos exibidos por um modelo é reproduzido na ausência do reforço direto - por exemplo, a indesejável utilização, por uma criança, de certas palavras proibidas. Sabemos também que novos padrð̃es de comportamento que não existiam no repertório de comportamentos do imitador podem emergir subitamente. As maiores controvérsias emanadas de praticamente todos os atuais esforços no campo da pesquisa, entre teóricos e pesquisadores da imitação e dos processos sociais de aprendizagem, centralizam-se na questão sobre quais as condiçðes necessárias para que uma pessoa adquira novas respostas por observação ou por imitação.

\section{ATRIBUTOS E VARIÁVEIS DA IMITAÇĀO}

Imitação é um tipo de fenômeno de aprendizagem por substituição ou suplementação, que inclui também identificação, cópia, simplificação social e dramatização. A diferenciação entre esses sub-processos ê feita à 
base de varífveis tais como a complexidade e o conteudo emocional da resposta emitida, as recompensas e suas fontes e a presença ou ausência de um modelo. Por exemplo, a imitação envolve a reprodução de respostas discont́nuas, separadas, enquanto que a identificação envolve a adoção de diversos, complexos e, muitas vezes, deliberados padrões de comportamento ou símbolos que representam o modelo. A concentração psíquica generalizada, no modelo, é o pró-requisito para a identificação, mas não é o essencial, ou poderá estar ausente na imitação. Alguns autores estabelecem diferenças entre esses sub-processos com base no tipo de recompensas, que podem ser intrínsecas ou extrínsecas. Outros afirmam que imitação é comportamento semelhante na presença de um modelo e reservam o termo identificação para o desempenho do comportamento do modelo em sua ausência $9,10$.

Bandura sustenta que, em essência, o processo de aprendizagem é o mesmo independentemente da generalidade do que é aprendido, dos modelos dos quais os padröes de respostas são adquiridos $e$ das condiçбóes extimuladoras sob as quais o comportamento imitativo é, subsequentemente, executado 11. Revê, em obra recente, numerosos estudos que demonstram duas idéias de capital importância: 1) as condiçðes antecedentes exigidas são as mesmas tanto para a aquisição de respostas semelhantes isoladas quanto de repertórios imitativos completos; 2) o processo de aquisição de respostas semelhantes na presença de um modelo é diferente daquele desempenhado posteriormente, em sua ausência 12 .

0 conceito de imitação utilizado neste artigo refere-se ao comportamento - novo, previamente adquirido, ou ambos que se efetua em resposta a estímulos de imitação. Este pode ser direto (face a face), simbólico (palavras) ou pictórico (filmes, televisão). 0 processo imitativo inclui tanto a copia automática de comportamento simples, descontínuos, quanto o desempenho de comportamentos complexos.

Recentes pesquisas sobre as variáveis que determinam a aquisição de comportamento semelhante mostram que cerca de quatro grupos de variáveis sempre resistiram ao escrutínio cientifico: os atributos do modelo, as características do sujeito, as condiçб̃es incentivadoras e o modelo versus tema do reforço. Essas variáveis são particularmente relevantes no desenvolvimento do conceito da imitação como estratégia de ensino.

Os atributos do modelo formam um dos grupos de variáveis. 
De acordo com o condicionamento social prévio do sujeito, é mais provável que os modelos de maior prestígio, competentes, de alto status social e poderosos, the despertem maior atenção; poderão provocar, portanto, maior número de comportamentos imitativos do que os modelos que não possuam esses atributos 13 .

Rosenbaum e Tucker salientam que na aprendizagem imitativa, o educando não só responde às sugestóes fornecidas pelo comportamento de um modelo, como possue, em potencial, sugestóes valiosas na forma de consequências ambientais da resposta do modelol 4 . Por exernplo, enfermeiras experientes, que aprenderam a reagir independentemente às sugestðes oferecidas pelo trabalho com um paciente diffcil, podem oferecer insinuaç⿸es indiretas, relevantes, para a orientação do comportamento de enfermeiras recém-graduadas, para as quais essas sugestð̌es são obscuras, diffceis, ou não discriminadas. $O$ aprendiz, ou enfermeira recém-graduada, pode também observar as consequências locais do comportamento e as gratificaçðes que possam ou não resultar para a enfermeira experiente, o modelo.

Para a variável competência do modelo funcionar, o observador deve conhecê-la. Na experiência de Rosenbaum e Tucker, competência foi definida como a demonstração que um indivíduo recebe, em reação ao seu comportamento, de que este foi correto. Esses autores planejaram medir o efeito dessa sugestão de competência no comportamento imitativo. Usando uma série fictrcia de corridas de cavalos em ambiente de laboratório, criaram condiçðes nas quais os individuos eram colocados com pares (os modelos) competentes, em $80 \%, 50 \%$ ou $20 \%$ das provas. Os resultados indicaram, como era previsto que quanto maior a competência do modelo, mais facilitada era a aprendizagem desejada.

O que se poderá dizer da competência, especialmente em resposta a sugestðes do meio ambiente, da maioria das docentes de enfermagem, como modelos? A pesquisa da própria autora, com uma amostra de 220 jovens enfermeiras, diplomadas em cursos superiores de enfermagem, mostrou que elas estavam desiludidas com os modelos das instrutoras de enfermagem, jovens também, e que se mostravam inseguras, sem vivência da situação de trabalho e inexperientes 15 . Para ser um modelo não é suficiente conhecer muito bem a teoria e poder servir de exemplo em comportamento no campo intelectual, tais como a investigação e a resolução de problemas. As novas enfermeiras de hoje exigem que seus modelos sejam capazes de reagir 
as sugestóes do sistema assistencial de saúde e que demonstrem eficiência na prática da enfermagem dentro desse mesmo sistema.

As caracteristicas do sujeito, que formam o segundo grupo de variáveis, podem determinar predisposiçðes para reação imitativa. Um número considerável de dados de investigação indicam que pessoas que são dependentes, sem auto-estima, incompetentes e que tenham sido frequentemente recompensadas por apresentarem comportamento imitativo, podem tornar-se muito sensiveis às sugestzes fornecidas pelo comportamento dos outros 16. Diferenças de sexos entre o modelo e o sujeito podem influenciar também no âmbito da observação e da imitação do comportamento do modelo, o que depende grandemente da reação desejada. Num clássico estudo sobre a imitação, por crianças, de comportamentos agressivos de modelos masculinos e femininos, Bandura, Ross e Ross 17, 18 encontraram como resultado que os meninos reproduziam substancialmente mais comportamentos agressivos do que as meninas (É provável que esse comportamento imitativo ligado ao sexo constitua uma possível explicação para o fato de ser tão dif́cil conseguir que estudantes de enfermagem do sexo feminino adotem $o$ comportamento, um tanto quanto agressivo, de se dirigirem aos médicos a fim de, com eles, discutirem os planos de cuidados de enfermagem).

As condiçōes incentivadoras - Outra variável importante para o conceito de imitação é constituída pela situação destinada a antecipar o reforço positivo, a fim de que se realiza o comportamento imitativo. Experiência de Bandura, em 1965 19, mostra o efeito que a antecipação de recompensas pode causar. Nesse estudo, crianças observaram um filme em que um modelo exibia uma seqüência de formas novas de agressão física everbal a Bobo, um grande boneco representando um palhaço. Como tratamento, numa primeira apresentação, o modelo foi punido após desempenhar o comportamento agressivo; noutra, o modelo foi recompensado com bom tratamento e profusão de elogios; numa terceira, nenhuma recompensa foithe dada. No teste após a apresentação do filme houve diferenças significativas de comportamento das crianças em cada uma das três condiçðes de reforço. As crianças do grupo em que o modelo foi recompensado e do grupo em que nada lhes aconteceu desempenharam espontaneamente um número significativamente maior e variado de reaçð̃es imitativas do que o grupo em que o modelo foi punido.

O desempenho de uma ação, porém, será o mesmo que apren- 
dizagem? Depois do teste, as crianças dos três grupos receberam incentivos para a reprodução do comportamento que haviam presenciado no filme, com o propósito de transformar em execução as reaçoes que haviam tido através da observação. Para se compreender a importância do reforço positivo antecipado na reprodução do comportamento imitativo, deve-se fazer, primeiro, a distinção entre aprendizagem e o simples desempenho de uma ação. Bandura, ao contrário de muitos defensores da teoria do comportamento, encara a aprendizagem como adoção de comportamentos semelhantes; e o desempenho de uma ação, como imitação ou representação do comportamento.

Outro propósito da experiência de Bandura, em 1965, foi demonstrar essa diferença. Segundo esse autor ... desde que a aprendizagem deve, necessariamente, ser inferida de um comportamento, presumia-se que as respostas reproduzidas sob a influência de incentivos positivos dariam um indice de aprendizagem relativamente preciso 20 . Os resultados indicaram que a introdução de incentivos positivos para as crianças havia anulado as diferenças de comportamento observadas anteriormente revelando, entre as crianças dos três grupos, uma quantidade equivalente de aprendizagem.

Enquanto que existe alguma evidência de que a promessa de recompensas pode afetar significativamente a probabilidade de um individuo executar açð̃es semelhantes, previamente aprendidas, dificilmente as conseqüências (recompensas) poderão constituir condição prévia necessária à aquisição do comportamento. Se uma pessoa for exposta à observação de determinado comportamento e depois prometerem-lhe recompensas para reproduzí-lo, sua aprendizagem inicial não será, necessariamente, afetada. Entretanto, no caso dessa pessoa observar que o modelo é recompensado freqüentemente, quando executa uma série de respostas (por exemplo, enfermeira eficiente elogiada e recompensada pela excelência do seu trabalho), a observação desse fato, se ocorrer recentemente, poderá determinar aumento de vigilância em relação a comportamentos posteriores do modelo. Bandura 21 afirma que $a$ antecipação do reforço positivo para reproduzir respostas semelhantes pode, portanto, influenciar indiretamente o curso da aprendizagem suplementar, pelo enfoque e intensificação da observação das respostas do modelo. Conclui que pesquisas sobre o assunto ... apoiam a teoria de que a adoção de comportamentos semelhantes é resultado, primariamente, de uma série de estrmulos e de processos simbólicos associados, onde a execuçāo dos comportamentos aprendidos através da observação dependerá muito da natureza das consequências do reforço (recompensas) sobre o modelo ou sobre o obser- 
uador 22.

Modelo versus reforço - é outra variável que tem recebido atençăo nas pesquisas sobre a aprendizagem social ou por imitação. Será que o modelo ou o reforço intensificam a aprendizagem imitativa? Pode ser empregado unicamente o reforço diferencial, a fim de determinar novos padrðes de comportamento, mas é um processo longo e traumatizante. Por exemplo, em experiência para avaliar a aprendizagem de uma seqüência complexa de comportamentos, Luchins e Luchins encontraram mais de mil erros em universitários que haviam recebido somente uma orientação superficial (feedback da forma correta, sem explicaçбes sobre os erros cometidos); esses estudantes nunca chegaram à execução plena do comportamento desejado. Por outro lado, os universitários que receberam reforço, aprenderam ra pidamente o comportamento e livraram-se da frustração evidenciada no outro grupo, submetida à aprendizagem por ensaio e erro 23 .

Creio que esse esquema é seguido, muitas vezes, pela aprendizagem mal orientada de descoberta. $\mathrm{Na}$ intenção de proporcionar ao estudante a oportunidade de sentir a emoção de descobrir por si novas idéias e novos conhecimentos, a estratégia de ensino toma a forma de uma aventura de esconde-esconde, em que o professor, deliberadamente, sonega informaçros. A utilidade da aprendizagem por descoberta e o desenvolvimento de estratégias de ensino a fim de aumentá-la, devem levar em consideração as variáveis definidas há muitos anos por Cronbach; isto é, devem ser efetuadas experiências com esse tipo de aprendizagem, a fim de determinar sua propriodade em relação a para determinado assunto, uma experiência indutiva de determinado tipo, em determinada proporção, produz um determinado padrũo de respostas, em alunos de determinado nivel de desenvolvimento 24.

Supondo que o reforço da imitação pode ser mais efetivo e eficiente do que o reforço diferencial, que efeito produzirá a imitação num estudante que já possui comportamentos dominantes pré-estabelecidos, que impedem a emissão das respostas secundárias desejadas? Esses comportamentos secundários não podem ser influenciados pelo reforço, pois raramente ocorrem espontaneamente. Como poderão, portanto, ser eficiente e efetivamente aprendidos?

Piaget sugeriu que os julgamentos morais seguem uma seqüência fixa de desenvolvimento. De acordo com essa teoria, podem ser distin- 
guidas duas fases distintas de julgamento moral, demarcadas uma da outra, aproximadamente, aos sete ou nove anos de idade. Na fase de responsabilidade objetiva, as crianças de mais ou menos cinco anos julgam da gravidade de um ato censurável pela quantidade de prejuízo material que acarretou, deixando de lado a intenção do ato. $\mathrm{Na}$ fase de responsabilidade subjetiva, que se acredita iniciar após os 7 anos, as crianças julgam da gravidade de um ato mais pela sua intenção, não tanto pelas conseqüências materiais 25 . Os fatores responsáveis pela transição de uma fase a outra ainda não foram bem esclarecidos, se bem que a seqüência das fases seja prefixada.

Em experiência realizada para testar a teoria do desenvolvimento de Piaget, Bandura e Mc Donald propuseram-se verificar se a orientação moral dominante em crianças poderia ser alterada, pela introdução de variáveis aprendidas no convívio social, ou mesmo invertida, pela manipulação do reforço, de acordo com modelos sociais apropriados. Para averiguar a orientação moral dominante de crianças do curso primário, um grupo delas foi submetida a um teste com 12 pares de histórias. Cada par descrevia um ato bem intencionado que resultava em grande prejuízo material e umato egoísta, motivado pela maldade, mas sem graves consequências. Por exemplo, na história A, João, ao obedecer o chamado da mãe para o jantar quebra, acidentalmente, quinze chícaras que estavam numa bandeja atrás da porta da sala de jantar; na história B, Henrique quebra uma chícara ao roubar doces, na ausência da mãe. Foi solicitado às crianças que dissessem qual dos dois meninos havia agido pior e por que. As crianças que apresentaram orientação moral subjetiva ou objetiva bem características foram reunidas em três grupos experimentais.

Um dos grupos foi exposto a modelos femininos adultos que expressavam sempre julgamento oposto à orientação moral dominante das crianças. Foram apresentados 12 pares de histórias (semelhantes às descritas acima): primeiro para o modelo e depois para a criança. $O$ modelo sempre recebia reforço; a criança o recebia toda a vez que adotava o julgamento moral do modelo. Em outro grupo, as condiçðes eram as mesmas, apenas a criança não recebia qualquer reforço quando adotava o julgamento do modelo. Num terceiro grupo, não havia modelos; a criança era recompensada toda a vez que adotava comportamento contrário à própria orientação moral dominante (um exemplo de condicionamento operante). 
12 pares de histórias, a fim de se obter maiores informaçð̃es sobre seus julgamentos na ausência dos modelos e do reforço social. A medida da aprendizagem consistia na porcentagem de respostas opostas à orientação moral dominante e pré-determinada da criança. Os resultados indicaram que as crianças que tiveram modelos para observar, bem como as que receberam reforço por imitarem o julgamento moral do modelo, modificaram significativamente sua própria orientação moral. $\mathrm{O}$ terceiro grupo de crianças apresentou um ligeiro aumento de respostas opostas, em número estatisticamente não significativo.

Ao contrário da previsão, a utilização apenas de modelos foi tão eficiente na mudança de julgamento das crianças, como a combinação de modelos com o reforço social direto. De acordo com o que se esperava, ficou provado que as duas situaçð̃es que envolviam processo de imitação foram muito mais poderosas que o condicionamento operante 26 .

Esse estudo demonstrou que a imitação é mais eficiente em produzir mudanças nos padrões de comportamentos dominantes e pré-existentes, do que o condicionamento operante; e ainda, que o reforço do modelo não é condição necessária para que a imitação ocorra. Será que nós, enfermeiras, estamos utilizando os conhecimentos existentes sobre o valor do reforço, a fim de apressar o processo de aprendizagem? Estaremos usando as melhores estratégias de ensino para conseguir isso? Em muitas das situaçбes do processo ensino-aprendizagem com adultos, pacientes ou estudantes, encontram-se atitudes ou comportamentos motores, pré-existentes, que talvez precisem ser anulados ou invertidos? Por exemplo, estudantes de enfermagem recém-admitidas muitas vezes possuem expectativas dominantes préestabelecidas com relação à enfermagem, considerando-a uma série de tarefas a serem executadas para os doentes. As respostas complementares, desejadas nesta situação, poderão ser o papel expressivo da enfermeira, zelosamente defendido pelas docentes das escolas universitárias de enfermagem. Pode ser considerado também o caso do paciente cardfaco que deve inverter sua atitude pré-existente em relação ao consumo de sal, ou o diabético obeso em relação à alimentação, e assim por diante.

\section{A estratégia de ensino pela imitação}

Como vimos, o reforço talvez seja da maior importância no 
processo de aprendizagem e, provavelmente, mais eficiente quando se observa que o modelo é recompensado, não o aluno. Entretanto, Bandura e Kupers mostraram que padrôes de auto-reforço também podem ser.ensinados através da imitação. Encontraram, em seu estudo, que: 1) os padrðes e a magnitude do auto-reforço do indivíduo aproximam-se muito do reforço proporcionado pelo modelo; 2) em geral, na transmissão de respostas de auto-reforço, os adultos servem de estímulo para imitação do que os companheiros do grupo 27. Portanto, um plano de estra tégia de ensino através da imitação deve focalizar: o reforço do modelo adulto em relação à competência (supondo, naturalmente, que será utilizado um modelo competente); fazer com que o modelo demonstre um padrão real de auto-reforço baseado em que, numa profissão, deseja-se a aquisição de normas especificas, interiorizadas, as quais os indivíduos sintam satisfação em observar; oferecer ao educando, antes de submetê-lo à experiência da imitação, uma indicação incentivadora (para apressar a adoção do comportamento desejado). Deve-se ter a preocupação de planejar sessðes de prática dos comportamentos ou habilidades motoras que o educando possa não ter adquirido ainda e que sejam indispensáveis à realização do comportamento desejado. Nessas circunstâncias, a pesquisa indica que provavelmente os esquemas de reforço diferencial são mais eficazes.

Que tipos e combinações de processos de imitação devem ser utilizados como exemplos de estratégia de ensino pela imitação? No estudo de Bandura, sobre a imitação de comportamento agressivo, foram usadas diversas abordagens - um modelo vivo, o mesmo modelo apresentado num filme e desenhos animados representando o comportamento agressivo. Os resultados mostraram que o modelo vivo e o filme produziram o mesmo nível de comportamento imitativo e que, com esses modelos, houve aprendizagem em grau muito mais significativo do que a verificada no grupo controle ou com a utilização dos desenhos animados 28 .

Creio que, toda a vez que os filmes são utilizados como estfmulo para imitação, o modelo deve ser uma pessoa com a qual o educando está familiarizado e com a qual possa associar as características importantes num modelo: prestígio, competência, etc..

Um outro problema: serão igualmente eficazes os modelos perceptivos (conscientes e com discernimento) e os simbólicos? Numa comparação desses dois tipos, com relação à aquisição de habilidade em ensinar 
como formular boas perguntas, Allen et al chegaram à conclusão de que, como agente de treinamento, um não é melhor que o outro 29 - evidentemente, ambos são potencialmente áteis.

Que tipos de exemplos devem ser apresentados quando houver a intenção de usá-los na estratégia de ensino através da imitação? Se determimada atitude foi a resposta imitativa desejada, por exemplo - a atitude em relação a pacientes alcoblatras, - pode ser desejável contar com modelos que respondam a uma grande variedade de atitudes que o público possa assumir. Outro exemplo se o objetivo de ensino é fazer com que os estudantes aprendam a trabalhar com pacientes deprimidos, estas deverão observar uma variedade de modelos em ação, cada um representando uma abordagem diferente, seja teórica ou pela atitude. $O$ importante é lembrar que o comportamento que pode ser mais eficiente em produzir a imitação, é o do modelo percebido como recompensado por ter correspondido às solicitaçðes do ambiente (isto $\mathcal{E}$, que demonstrou ter competência).

\section{Exemplo de imitação como estratégia de ensino}

Todas as pesquisas descritas no presente artigo foram feitas em laboratório, fora do ambiente natural, na maior parte utilizando crianças. Como poderfamos aplicar os resultados ao ensino de estudantes de enfermagem e de pacientes?

Hilgard nos mostra o caminho em sua descrição dos seis passos, da pesquisa científica pura à prática educacional estabelecida. Utiliza, como base de sua série contínua, o grau de relevância para o empreendimento educacional com o mais puro (pesquisa em laboratório, com animais) numa extremidade da série, e pesquisa em ambiente natural, com população relevante e a matéria ou o assunto, na outra 30. Esse último tipo é extremamente necessário para ambas, enfermagem e educação geral, especialmente nos processos sociais de aprendizagem.

Recentemente tentamos por em prática com o auxflio de uma colega, alguns dos resultados das pesquisas citadas anteriormente; esse trabalho estava associado a uma subvenção destinada a desenvolver e melhorar as estratégias de ensino, num currículo orientado no sentido da sistematização burocrática. Levaram-nos a essa tentativa as discussões que mantínhamos sobre as atitudes negativas das estudantes em relação a seu papel como 
agente de mudanças em potencial, e sua insatisfação em cuidar dos pacientes internados em enfermaria geral médico-cirúrgica. Pelo que sabemos, essa foi a primeira vez que a imitação foi conscientemente utilizada como a principal estratégia de ensino num programa universitário de enfermagem.

Havíamos observado que a apatia generalizada entre as enfermeiras do serviço, a falta, no campo clínico, de bons modelos que demonstrassem gosto e entusiasmo pela enfermagem, e a falta de modelos que desempenhassem tanto o papel expressivo quanto o instrumental da enfermeira, tudo isso atrasava o processo de aprendizagem social da estudante. Estávamos particularmente preocupados com o papel da professora no campo clínico.

$\mathrm{O}$ método usual de ensino entre as nossas docentes deve ser o mesmo utilizado na maioria das escolas de enfermagem. A docente é responsável por cerca de dez alunas, cada uma das quais deve planejar e dar cuidados a um ou dois pacientes. A aluna procura a docente para orientação, em caso de necessidade. Como uma espécie de bombeiro, a docente corre de uma aluna em crise para outra, respondendo perguntas, orientando, mostrando uma coisa aqui, outra lá, assim por diante. Emprega medidas preventivas entre uma crise e outra, fazendo perguntas e assegurando-se de que a estudante sabe o que está fazendo e de que conhece os princípios fundamentais em que se baseia aquele tipo de atividade. Infelizmente, isto deixa muito pouco tempo para a docente utilizar no cuidado direto ao paciente. Poderá dar alguma assistência no decorrer do seu trabalho com as estudantes, mas limitada e dirigida mais à demonstração ou supervisão do cuidado.

$\mathrm{O}$ relacionamento entre a docente e as enfermeiras do serviço varia de acordo com as pessoas envolvidas. Geralmente prevalece uma política de mantenha-se no seu lugar - as estudantes constituem responsabilidade da docente para o ensino, a disciplina e a recompensa. Muitas vezes, o único contato importante entre estudantes e enfermeiras da clínica se dá quando uma destas chama a atenção da aluna e da docente para eventuais falhas na enfermaria.

Nossa escola, como muitas dentre as universitárias, dá ênfase ao papel expressivo da enfermeira e tenta socializar as estudantes em relação ao sistema profissional de organização do trabalho - de executar o trabalho que deve ser executado. Esta abordagem é possível com esse tipo de estudantes por que recebem tarefas limitadas na enfermaria e são afastadas, pela do- 
cente, da burocracia do sistema. Dentro das limitaçðes do sistema, raramente, portanto, as alunas tem oportunidade de aprender como prestar assistência da enfermagem de qualidade.

Creio que as estudantes devem aprender isto e que uma boa instrutora, capaz de demonstrar como pode ser feito, arranjará um jeito de dar à estudante a oportunidade de aprender por imitação. Com essa finalidade planejamos, minha colega e eu, uma estratégia experimental de ensino. 0 comportamento imitativo que desejávamos como resposta era a colaboração universitária entre estudantes, pessoal de enfermagem, médicos e docentes. A assistente desse projeto, enfermeira clínica muito capaz, tinha sido membro do corpo docente. As estudantes gostavam dela, respeitavam-na e a consideravam uma verdadeira enfermeira de campo. Minhas colegas do corpo docente e eu achávamos que ela possuía muitas das qualidades de um modelo, necessárias para demonstrar a possível eficiência da imitação como estratégia de ensino.

Essa enfermeira solicitou trabalho junto a um grupo regular de nove estudantes de $1^{\circ}$ ano, que estavam tendo experiência "em enfermagem médico-cirúrgica numa enfermaria de 40 leitos, em um grande hospital distrital. $\mathbf{O}$ ambiente $e ́$ importante por que a instrutora-modelo era conhecida e respeitada nessa instituição (havia trabalhado como instrutora e como en. fermeira de campo); a enfermaria, grande e aberta, permitia a necessária visibilidade para que houvesse aprendizagem por imitação.

A instrutora-modelo sentia-se competente e era assim julgada pelas colegas e pelos médicos da enfermaria; gozava, também, de grande prestígio. As estudantes sabiam que havia sido membro do corpo docente; que naquela ocasião, trabalhava com subvenção federal; e que elas estavam envolvidas num estudo especial sobre um novo método de ensino.

A instrutora-modelo entrou em contato, primeiro, com as enfermeiras da clínica e explicou-lhes que ia experimentar um novo método de ensino, pedindo sua colaboração. Depois reuniu-se com as estudantes e disse-lhes a mesma coisa, solicitando auxílı na avaliação do método e advertindo sobre a possível dificuldade em ajustarem-se a ele. Explicou que, ao invés de circular entre as alunas fazendo perguntas, orientando e ajudando-as

- Estágio intermediário, isto e, o segundo em enfermagem médico-cirúrgica. 
ia, pessoalmente, prestar assistência a um paciente. Estaria à disposiçăo para conselhos, avaliação e auxflio, mas as proprias estudantes deveriam procurála para isso. Orientou o grupo no sentido de solicitar o auxllio das enfermeiras da clínica, quando necessário. Estabeleceu que as estudantes, pela manha, deveriam submeter-lhe os planos provisorios de cuidados de enfermagem; depois destes revisados, cada uma poderia começar o trabalho do dia por sua própria conta, a única limitação consistindo em mostrar-lhe a medicaçăo endovenosa e narcótica antes de administrá-la.

O objetivo de criar uma situação como essa foi para dar à instrutora a oportunidade de servir de modelo para as estudantes e para as enfermeiras da clínica, no que referia a assistência de enfermagem de boa qualidade, e de demonstrar como isso podia ser feito dentro de um sistema de trabalho burocraticamente organizado. Além disso, as estudantes podiam observar a instrutora quando esta discutia aspectos do cuidado, de enfermagem, ou quando solicitava orientação do médico, das enfermeiras e das próprias alunas.

Durante a reunião de planejamento insistiu-se em que as enfermeiras discutissem livremente $o$ assunto com a instrutora e com as alunas. Esperava-se que isso desse ao modelo o reforço, considerado muito eficaz pelas pesquisas sobre os processos de aprendizagem social; esperava-se também que as estudantes passassem a reconhecer as oportunidades que 0 ambiente da enfermaria lhes oferecia.

$\mathrm{Na}$ manhã do primeiro dia a instrutora revisou os planos de cuidados e começou a cuidar dos seus próprios pacientes. Tanto as estudantes quanto as enfermeiras da clínica pareciam nãoacreditar no fato e mostraram-se inconfortáveis com sua rápida mudança de papel. Passaram-se duas horas. Por fim, uma estudante aproximou-se da instrutora-modelo e fez-lhe uma pergunta; mais tarde, a instrutora pediu a uma das alunas que ajudass: a manter o seu paciente em posiçăo enquanto lhe lavava as costas; um médico discutiu com ela assunto sobre o qual havia feito uma observação; uma das alunas dirigiu-se à enfermeira da clínica a fim de perguntar-the sobre o encaminhamento de um dos seus pacientes a uma enfermeira de saúde pública, em virtude da instrutora modelo (docente) estar ocupada com o seu próprio paciente. $O$ projeto estava lançado.

Os resultados foram interessantes e satisfatórios. As estudantes 
sairam-se tão bem nas provas e exames como as demais de sua classe; não houve erro na administração de medicamentos, nem acidentes, grandes omissces ou problemas graves durante o perfodo de 10 semanas; as enfermeiras e os médicos da clínica ficaram entusiasmados. $O$ mais importante foi que as alunas disseram que haviam gostado da experiência, aprendido uma porf̧ão de coisas e que haviam, realmente, despertado para a enfermagem. Evidentemente, nenhum desses resultados pode ser atribuído ao efeito de Hawthorne; este estudo necessita ser repetido em pesquisa de campo bem planejada. Nossos resultados, porém, indicaram que esse tipo de situação imitativa pode muito bem constituir uma eficiente estratégia de ensino.

São dignas de menção duas outras maneiras pelas quais a estratégia de ensino através da imitação pode ser usada no ensino da enfermagem. Estimulado pelo relatório de Bandura e Walters 31, o corpo docente da Columbia Britânica, em Vancouver, tem selecionado modelos funcionais numa variedade de situaçóes de enfermagem (reservas de índios, hospitais rurais, áreas urbanas) enviando-lhes estudantes para um mês de observaçâo de campo, no final do seu primeiro ano na escola. $O$ objetivo é oferecer às alunas um extenso e intenso contato com as realidades do trabalho universal. Esse grupo de docentes está satisfeito com os resultados obtidos.

Há quatro anos, a Escola de Enfermagem da Universidade da California, em Såo Francisco, selecionou modelos funcionais para estudantes do 39 ano, durante a experiência de trabalho em equipe e, para cada uma designou um modelo dentre as enfermeiras da própria clínica. Isto, não só dá um certo grau de prestígio e gratificação à enfermeira que está sendo imitada como permite, aos membros do corpo docente que escolhem as enfermeiras que vão servir de modelo, exercerem alguma influência sobre a qualidade da assistência de enfermagem.

\section{Futuras aplicą̧ões}

Reinhemeyer conclui que, ao contrário do que se esperava, as diplomadas por escolas universitárias não vêm exercendo influência no desenvolvimento básico da prática da enfermagem 32. Berkowitz e Malone sustentam que a tarefa da geração atual de enfermeiras universitárias consiste num esforço de colaboração no sẹtido de modificar seu próprio comportamento, para que a aprendizagem das estudantes de enfermagem possa também ser modificado. Quando isto se der, as alunas passarão a ter os modelos funcio- 
nais de que tanto necessitam 33 .

Por enquanto, as enfermeiras universitárias ainda não tiveram a oportunidade que merecem. Não podemos esperar que todos os modelos funcionais provenham de enfermeiras que, provavelmente, nunca tiveram modelos funcionais a quem imitar. As estudantes universitárias de hoje devem ser orientadas por docentes que possam demonstrar como prestar boa assistência de enfermagem dentro do atual sistema assistencial de saúde; devem ter a oportunidade de imitar esses modelos, que poderão mostrar-lhes como produzir mudanças dentro desse mesmo sistema. A estratégia de ensino pela imitação pode ser uma maneira de conseguir isto. 